doi:10.4149/gpb_2010_02_151

\title{
Desmopressin stimulates bile secretion in anesthetized rats
}

\author{
Sepideh Parchami Ghazaee, Zoya A. Gorenko, Ludmila S. Karbovska, Stanislav P. Veselsky, \\ Petro I. Yanchuk and Mykola Y. Makarchuk \\ Department of Human and Animal Physiology, Faculty of Biology, National Taras Schevchenko University of Kyiv, Ukraine
}

\begin{abstract}
One of the synthetic analogues of antidiuretic hormone - desmopressin is used in patients with central diabetes insipidus and in those with coagulation disorders. However, its effects on bile secretion are not fully defined. We investigated the effect of desmopressin on bile formation and determined the role of $\mathrm{V}_{1 \mathrm{a}}$ vasopressin receptors in the action of desmopressin on choleresis. Rats were injected intraportally with a bolus of desmopressin; the changes of bile flow, the content of free and conjugated cholates were compared with control animal group. Selective antagonist of $V_{1 a}$ receptors was injected 10 minutes before desmopressin treatment and the findings were compared with the results after desmopressin injection alone. Desmopressin increased bile flow, secretion of total cholates like amino acids conjugated, while diminished free bile acids content. Secreted bile volume and conjugated bile acids content were reduced in $\mathrm{V}_{1 \mathrm{a}}$ receptors antagonist+desmopressintreated rats. In contrast, free bile acids content was more than the results in desmopressin-treated rats. Desmopressin at concentrations nearly equal to physiological concentrations of natural hormone in blood shows its choleretic effect. Antagonist of $\mathrm{V}_{1 \mathrm{a}}$ vasopressin receptors modulates desmopressin action. This certifies the role of these receptors in the action of desmopressin on different processes of bile formation.
\end{abstract}

Key words: Peptide — Desmopressin — Total bile acid — Conjugated bile acid — Free bile acid

\begin{abstract}
Abbreviations: ADH, antidiuretic hormone; DDAVP, 1-desamino-8-D-arginine vasopressin; TCA, taurocholic acid; TCDCA, taurochenodeoxycholic acid; TDCA, taurodeoxycholic acid; GCA, glycocholic acid; GCDCA, glycochenodeoxycholic acid; GDCA, glycodeoxycholic acid; CA, cholic acid; CDCA, chenodeoxycholic acid; DCA, deoxycholic acid; PIP $_{3}$, phosphatidylinositol 1,4,5-triphosphate; $\mathrm{IP}_{3}$, inositol 1,4,5-trisphosphate; DAG, diacylglycerol; PKC, protein kinase C; ACTH, adrenocorticotropin hormone; cMOAT, canalicular multispesific organic anion transporter proteins of bile acids; $\mathrm{Mrp}_{3}$, multidrug resistance-associated protein 3.
\end{abstract}

\section{Introduction}

Neuropeptides are bioactive substances that play an important role in regulation of different functions in body. Vasopressin or antidiuretic hormone $(\mathrm{ADH})$ is a very important regulatory peptide formed primarily in hypothalamus (Barberis et al. 1998). This hormone affects three different types of $\mathrm{V}_{1 \mathrm{a}}, \mathrm{V}_{1 \mathrm{~b}}\left(\mathrm{~V}_{3}\right)$, and $\mathrm{V}_{2}$ receptors, distributed in numer-

Correspondence to: Sepideh Parchami Ghazaee, Department of Human and Animal Physiology, Faculty of Biology, National Taras Schevchenko University of Kyiv, Volodymyrska 64, 01601 Kyiv, Ukraine

E-mail: SEP_PAR_71@yahoo.com ous tissues in different human and animal organs (Robert and Clauser 2005). ADH via activation of $\mathrm{V}_{1 \mathrm{a}}$ vasopressin receptors regulates many important biochemical processes in liver. Liver blood flow (Wang et al. 1997), glycogenolysis and gluconeogenesis (Montero et al. 2006) all are regulated by $\mathrm{ADH}$. $\mathrm{ADH}$ in the perfused rat liver increases bile flow (Serriere et al. 2001) and in the isolated rat hepatocyte couplets enhances bile secretory pressure and permeability of hepatocyte tight junctions (Nathanson et al. 1992a; Schiff et al. 1999). ADH decreases bile lipid secretion and canalicular secretion of taurocholate in cultured hepatocytes (Divald et al. 1994; Schiff et al. 1999). This hormone affects water and $\mathrm{Na}^{+}, \mathrm{Ca}^{2+}$ exchange in liver tissue (Lidofsky et al. 1993), although does not alter biliary bicarbonate in normal rat 
liver (Hirata and Nathanson 2001). Synthetic analogues of $\mathrm{ADH}$ are commonly used in clinical practice. One of these analogues, 1-desamino-8-D-arginine vasopressin (DDAVP) or desmopressin is a modified form of the normal hormone with minimal vasoconstrictive properties and longer half life (1.5-2.5 hours). DDAVP is used to reduce urine production in patients with central diabetes insipidus and to promote the release of von Willebrand factor and factor VIII in patients with coagulation disorders such as type I von Willebrand disease, mild hemophilia A, and thrombocytopenia (Agerso et al. 2004). However, its effects on bile secretion in liver are not fully defined. DDAVP is considered a standard vasopressin $\mathrm{V}_{2}$ receptor selective agonist, but recent studies have revealed that DDAVP acts as an agonist on human $\mathrm{V}_{1 \mathrm{~b}}$ and $\mathrm{V}_{1 \mathrm{a}}$ vasopressin receptors (Agerso et al. 2004; Saito et al. 1997). Since hepatocytes in rats are moderately rich in $\mathrm{V}_{1 \mathrm{a}}$ vasopressin receptors (Tran et al. 1999a,b), the purpose of this study is to show the effect of DDAVP on bile secretion and to determine the role of $\mathrm{V}_{1 \mathrm{a}}$ vasopressin receptors in mediating the effects of DDAVP on choleresis in vivo in rats.

\section{Materials and Methods}

Study has been done in acute experiments on 30 linear, male, young, mature Wistar rats (obtained from Institute of Gerontology, Academy of Medical Sciences of Ukraine, Kyiv, Ukraine), weighing 190-240 g, after 18 hours of food deprivation. Every rat was anesthetized with thiopentalumnatrium (Ukraine, OAO «Kyivmedpreparat», $7 \mathrm{mg} / 100 \mathrm{~g}$ rat b.w.). Common bile duct was then cannulated with polyethylene catheters, respectively. In first series of experiments, rats were injected intraportally with a bolus of a synthetic analogue of ADH, DDAVP (Sigma, USA, $1 \mathrm{ng} / 100 \mathrm{~g}$ rat b.w.). The animals in control group were injected intraportally with sodium chloride $0.9 \%(0.1 \mathrm{ml} / 100 \mathrm{~g}$ rat b.w.). In order to determine the effect of DDAVP in presence of $\mathrm{V}_{1 \mathrm{a}}$ vasopressin receptors antagonist on choleresis, in second series of experiments, rats were injected intraportally with a selective antagonist of $\mathrm{V}_{1 \mathrm{a}}$ vasopressin receptors, $[\beta$-mercapto- $\beta, \beta$ cyclopentamethylenepropionyl, O-me-Tyr, Arg]vasopressin, $\geq 97 \%$ (HPLC) (Sigma, USA, $1 \mu \mathrm{g} / 100 \mathrm{~g}$ rat b.w.) 10 minutes before DDAVP administration and the findings were compared with the results after DDAVP treatment alone. All treatments were performed after stabilizing the level of bile flow (30 minutes). Secreted bile was collected every 30 minutes during 3 hours of the experiment by micropipette connected to cannula located in bile duct. Bile flow was calculated by $\mu$ l bile per $g$ rat body weight.

Free and conjugated bile acids were divided by thin layer chromatography method that has been described by Veselsky et al. (SU 1624322 A1 copyright certificate description No.
4411066/14 IPC G 01 N 33/50. A method for determination of bile acids in biological liquid. Veselsky S. P., Lyashchenko P. S., Lukyanenko I. A.). For this purpose, $0.1 \mathrm{ml}$ of bile was added to $1.9 \mathrm{ml}$ of cold, extracted mixture of ethanol and acetone $(1: 3)$. Samples were kept $\operatorname{cool}\left(-10\right.$ to $\left.0^{\circ} \mathrm{C}\right)$ in an ice chamber for 25-30 minutes and then centrifuged for 10-12 minutes at 3000-4000 r.p.m.. The extracts were then poured in conoid glass test tubes and dried at $37-40^{\circ} \mathrm{C}$ to get dry remainders. Dry remainders were dissolved in $50-100 \mu$ l of ethanol-water mixture (6:4). 5-10 $\mu$ l of samples were inflicted on the preliminary washed and marked chromatography plates $(15 \times$ $15 \mathrm{~cm}$, silica gel plates on aluminium back, Kavalier, Czech). Free and conjugated bile acids deviation was carried out in the system containing amyl ester acetic acid, toluole, butanole, acetic acid and water $(3: 1: 1: 3: 1$, respectively), in glass chromatography chambers. Chromatograms were dyed after five times sprinkling from a glass fine-disperser pulveriser with the dye stuff ( $15 \mathrm{ml}$ icy acetic acid, 1 g phosphomolybdic acid, $1 \mathrm{ml}$ sulphuric acid and $5 \mathrm{ml}$ of $50 \%$ trichloroacetic acid solution). Chromatograms were put at $60-70^{\circ} \mathrm{C}$ during 5 minutes. Quantitative determination of bile acid content was performed by densitometer GP-920 (Shimadzu, Japan) under reflected light $(\lambda 620 \mathrm{~nm})$. This method allowed dividing mixture of bile acids into following fractions: TCA, TCDCA+TDCA, GCA, GCDCA+GDCA, CA, CDCA+DCA. Bile acids content was calculated by mg per $\mathrm{g}$ of rat body weight.

Statistical analysis of results was performed with the statistical package Statistika version 6.0. Results are expressed as means \pm SEM. Comparison between experimental groups was performed with Student's t-test for normally distributed values (Shapiro-Wilk's W test). $p<0.05$ was considered significant.

This study was conducted according to the decision held by Biological Ethics Committee, Faculty of Biology, National Taras Schevchenko University of Kyiv (protocol No. 3 from April 9, 2009). This work has been done in accordance with Declaration of Helsinki (World medical assembly, 1964), Declaration of Principles on Tolerance (28th session of UNESCO, 1995), Universal Declaration on Bioethics and Human Rights related to introduction of new biomedical technologies, accepted in 1997 in the city of Oviedo (Spain) and signed by parliament of Ukraine in 2002, Law of Ukraine No. 3447 IV "About animals protection from brutal behavior".

\section{Results}

\section{Influence of DDAVP on bile flow in rats}

As illustrated in Fig. 1, under the effect of DDAVP the level of bile secretion was steadily increased in most samples with significant deviations during 3 hours in comparison with changes in control rats. 


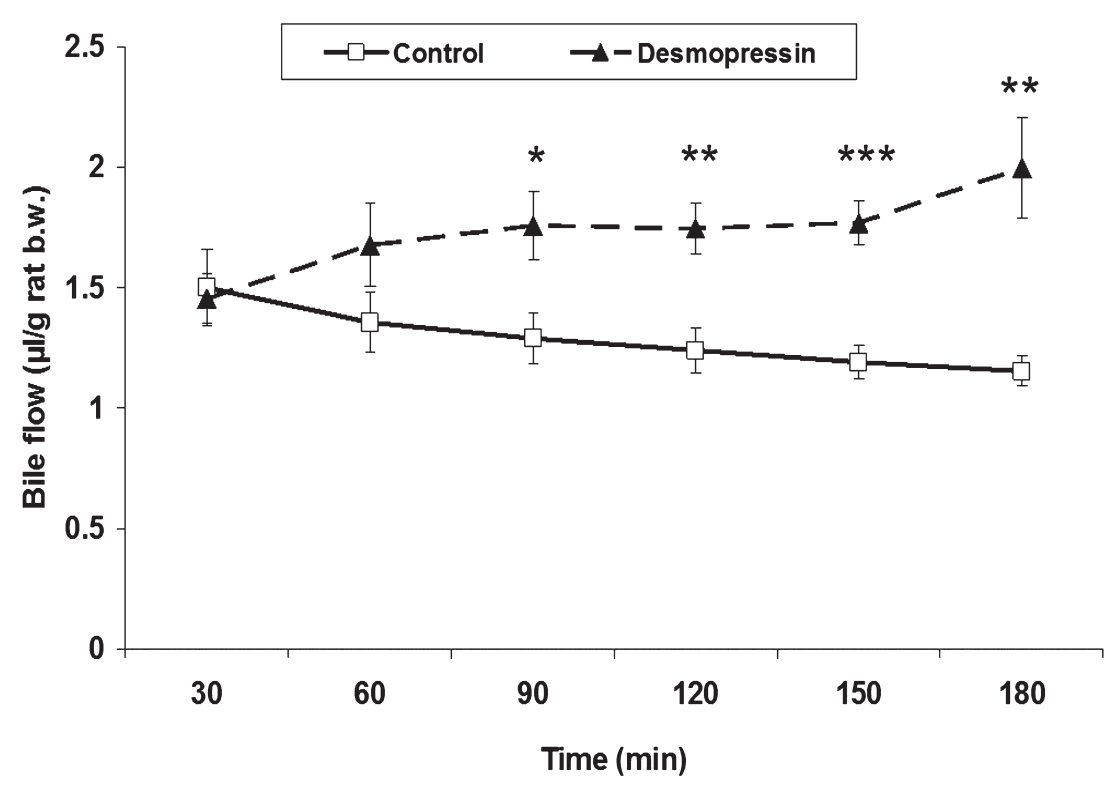

Figure 1. Effect of desmopressin on bile flow. Bile samples were collected every 30 min during 3 hours of the experiment. Means \pm SEM; $n=18 ;{ }^{*} p<0.05 ;{ }^{* *} p<0.01 ;{ }^{* *} p<0.001$ as compared with control rats.

Total secreted bile volume in overall time of the experiment was increased by $34.5 \%$ (from $7.7 \pm 0.6 \mu \mathrm{l} / \mathrm{g}$ to $10.4 \pm$ $0.8 \mu \mathrm{l} / \mathrm{g} ; p<0.05)$ in comparison with control data.

\section{Influence of DDAVP on bile acid secretion in rats}

In DDAVP-treated rats, the content of total bile acids was not significantly altered in the first and the second half-hour samples. Meanwhile this index was significantly enhanced in the last two hours of the experiment as compared with control data (Fig. 2). The total bile acids content in the entire time of the experiment was changed by $54.1 \%$ (from $31.8 \pm$ $2.8 \mathrm{mg} / \mathrm{g}$ to $49.1 \pm 2.8 \mathrm{mg} / \mathrm{g} ; p<0.01$ ).

It is necessary to note that DDAVP stimulated secretion of total taurine and glycine conjugated bile acids. Under the effect of peptide no significant changes were obtained in the first and the second half-hour samples. DDAVP caused a marked increase in

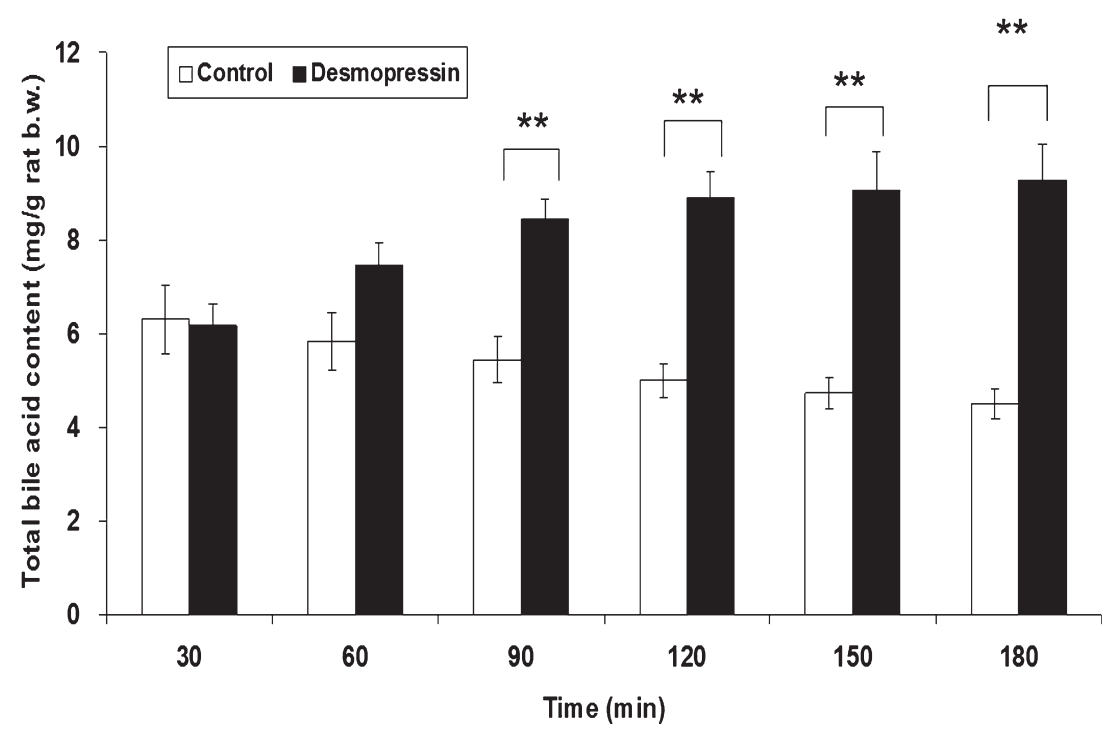

Figure 2. Effect of desmopressin on total bile acids content. Secreted bile was collected each half-hour during 3 hours of the experiment. Means \pm SEM; $n=18 ;{ }^{* *} p<0.01$. 


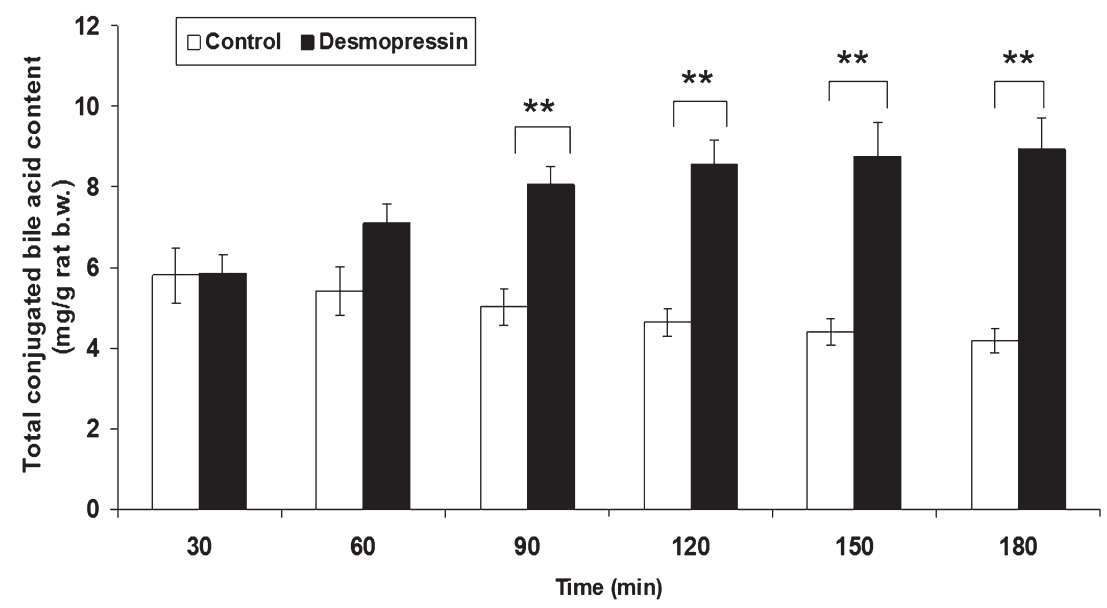

Figure 3. Effect of desmopressin on total conjugated bile acids content. Secreted bile was collected each half-hour during 3 hours of the experiment. Means \pm SEM; $n=18 ;{ }^{* *} p<0.0$.

the third half-hour by $60.2 \%(p<0.01)$, in the fourth by $84.1 \%$ $(p<0.01)$, in the fifth by $94.1 \%(p<0.01)$ and in the sixth by $113.4 \%(p<0.01)$ as compared with control rats (Fig. 3$)$. The content of total conjugated bile acids in the entire time of the experiment by $59.4 \%$ (from $29.5 \pm 2.7 \mathrm{mg} / \mathrm{g}$ to $47.1 \pm 3 \mathrm{mg} / \mathrm{g}$; $p<0.01$ ) was higher than the results in the control group.

The main composition in the increased content of total conjugated cholates within bile was taurine-conjugated bile acids. The content of TCA was insignificantly increased only during the first half-hour sample and in the other samples toward the end of the experiment was significantly changed. The most significant increase was observed in the fourth half-hour sample by
$79.9 \%(p<0.001)$ and in the fifth by $88.1 \%(p<0.001)$ (Table 1$)$. TCA content in overall time of the experiment was increased by $57.4 \%(p<0.01)$ as compared with control data.

DDAVP-treated rats exhibited an increase in biliary TCDCA+TDCA efflux in all 3 hours of the experiment. Significant changes were evident from the second half-hour toward the end of the experiment. The most significant increase was observed in the third half-hour by $82.9 \%(p<0.001)$ and in the fourth by $112.6 \%(p<0.001)$ as compared with the results in control rats (Table 1). In overall time of the experiment, the content of TCDCA+TDCA within bile was enhanced by $80.5 \%(p<0.01)$.

Table 1. Changes of conjugated bile acids content (mg/g b.w.) under the effect of desmopressin (DDAVP, $1 \mathrm{ng} / 100 \mathrm{~g}$ b.w.)

\begin{tabular}{|c|c|c|c|c|c|}
\hline $\begin{array}{c}\text { Time of } \\
\text { incubation } \\
(\min )\end{array}$ & & $\begin{array}{c}\text { TCA } \\
\text { (mg/g b.w.) }\end{array}$ & $\begin{array}{c}\text { TCDCA+TDCA } \\
\text { (mg/g b.w.) }\end{array}$ & $\begin{array}{c}\text { GCA } \\
\text { (mg/g b.w.) }\end{array}$ & $\begin{array}{c}\text { GCDCA+GDCA } \\
\text { (mg/g b.w.) }\end{array}$ \\
\hline \multirow{2}{*}{30} & Control & $2.3 \pm 0.27$ & $1.3 \pm 0.16$ & $1.9 \pm 0.25$ & $0.3 \pm 0.04$ \\
\hline & DDAVP & $2.4 \pm 0.14$ & $1.4 \pm 0.09$ & $1.8 \pm 0.19$ & $0.4 \pm 0.06$ \\
\hline \multirow{2}{*}{60} & Control & $2.1 \pm 0.23$ & $1.2 \pm 0.13$ & $1.8 \pm 0.23$ & $0.3 \pm 0.03$ \\
\hline & DDAVP & $2.8 \pm 0.11^{\star}$ & $1.8 \pm 0.10^{*}$ & $2.1 \pm 0.23$ & $0.4 \pm 0.07$ \\
\hline \multirow{2}{*}{90} & Control & $1.1 \pm 0.18$ & $1.1 \pm 0.09$ & $1.7 \pm 0.18$ & $0.3 \pm 0.04$ \\
\hline & DDAVP & $3.1 \pm 0.10^{\star *}$ & $2 \pm 0.10^{* * *}$ & $2.4 \pm 0.23^{*}$ & $0.5 \pm 0.08^{*}$ \\
\hline \multirow{2}{*}{120} & Control & $1.8 \pm 0.13$ & $1 \pm 0.07$ & $1.5 \pm 0.14$ & $0.3 \pm 0.03$ \\
\hline & DDAVP & $3.3 \pm 0.15^{* * *}$ & $2.2 \pm 0.16^{* * *}$ & $2.5 \pm 0.24^{*}$ & $0.5 \pm 0.09^{*}$ \\
\hline \multirow{2}{*}{150} & Control & $1.8 \pm 0.14$ & $0.1 \pm 0.07$ & $1.5 \pm 0.13$ & $0.2 \pm 0.03$ \\
\hline & DDAVP & $3.3 \pm 0.20^{* * *}$ & $2.2 \pm 0.20^{* *}$ & $2.4 \pm 0.21^{* *}$ & $0.5 \pm 0.09^{*}$ \\
\hline \multirow{2}{*}{180} & Control & $1.7 \pm 0.12$ & $0.9 \pm 0.08$ & $1.4 \pm 0.12$ & $0.2 \pm 0.02$ \\
\hline & DDAVP & $3.5 \pm 0.29^{\star *}$ & $2.3 \pm 0.23^{* *}$ & $2.6 \pm 0.23^{* *}$ & $0.5 \pm 0.10^{*}$ \\
\hline
\end{tabular}

Means \pm SEM; $n=18$, as compared with changes in control rats. DDAVP, desmopressin; TCA, taurocholic acid; TCDCA+TDCA, mixture of taurochenodeoxycholic acid+taurodeoxycholic acid; GCA, glycocholic acid; GCDCA+GDCA, mixture of glycochenodeoxycholic acid+glycodeoxycholic acid; ${ }^{*} p<0.05 ;{ }^{* *} p<0.01$; $^{* *} p<0.001$. 


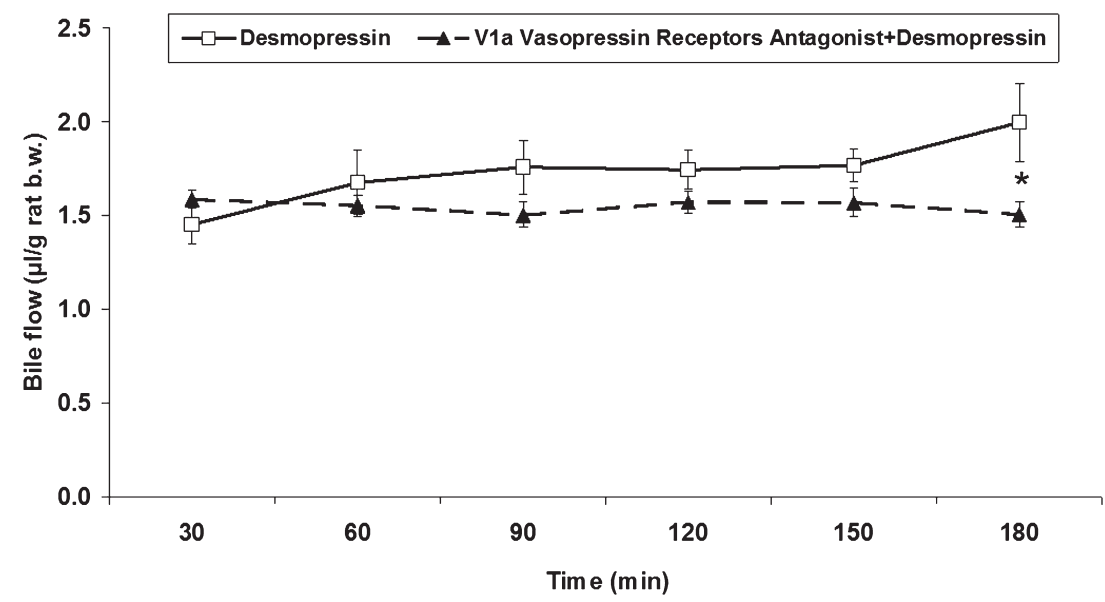

Figure 4. Effect of desmopressin on bile flow in $\mathrm{V}_{1 \mathrm{a}}$ vasopressin receptors antagonist+desmopressin-treated rats. Secreted bile was collected each half-hour during 3 hours of the experiment. Means \pm SEM; $n=18 ;{ }^{*} p<0.05$ as compared with desmopressin-treated rats.

Mostly under the effect of DDAVP, the content of GCA was modified. This index in the first and the second half-hour samples of the experiment was not significantly changed. Meanwhile it was significantly increased in the last two hours of the experiment as compared with control animals (Table 1). The stimulatory effect of DDAVP on total GCA content in the entire time of the experiment was about $43.1 \%$ $(p<0.05)$.

The content of GCDCA+GDCA, in response to DDAVP treatment, was higher than in the control rats. Significant statistical changes were observed in the last two hours of the experiment (Table 1). The total GCDCA+GDCA content in the entire time of the experiment was increased by $85.8 \%(p<0.05)$.

On the contrary, after DDAVP treatment free bile acids content was diminished. As shown in Table 2, no significant differences were observed in CA content in most samples of the experiment, although in the first half-hour it was significantly less than in the control rats (by $35.3 \% ; p<0.05$ ). The total CA content in the entire time of the experiment was insignificantly changed.

Similar differences were observed in the changes of $\mathrm{CDCA}+\mathrm{DCA}$ content. This index was significantly decreased by $38.8 \%(p<0.05)$ in the first half-hour sample (Table 2$)$.

The current data revealed that, under the effect of DDAVP $(1 \mathrm{ng} / 100 \mathrm{~g}$ rat b.w.) the total bile acids content, including both total tauro- and glycocholates content within bile were enhanced, while this peptide on free bile acids secretion had an opposite effect.

Role of $V_{1 a}$ vasopressin receptors in mediating the effects of DDAVP on bile secretion in rats

To determine the role of $\mathrm{V}_{1 \mathrm{a}}$ vasopressin receptors in mediating the effects of DDAVP on bile secretion, we examined the effect of DDAVP on bile secretion in presence of the selective $\mathrm{V}_{\text {la }}$ vasopressin antagonist and compared the findings with the obtained results under the effect of DDAVP alone. The results of our study revealed that the secreted bile volume was reduced, although it was significantly altered only in the last half-hour sample by $24.5 \%(p<0.05)$ (Fig. 4).

The biochemical analysis of bile showed that under the effect of DDAVP in presence of $V_{1 a}$ vasopressin receptors antagonist, TCA content was insignificantly changed at the first hour of the experiment and during the subsequent two hours was significantly decreased. This index in the entire

Table 2. Changes of free bile acids content (mg/g b.w.) under the effect of desmopressin (DDAVP, $1 \mathrm{ng} / 100 \mathrm{~g}$ b.w.)

\begin{tabular}{cccc}
\hline $\begin{array}{c}\text { Time of } \\
\text { incubation } \\
(\mathrm{min})\end{array}$ & & \multicolumn{1}{c}{$\begin{array}{c}\text { CA } \\
(\mathrm{mg} / \mathrm{g} \text { b.w. })\end{array}$} & $\begin{array}{c}\text { CDCA+ DCA } \\
(\mathrm{mg} / \mathrm{g} \text { b.w. })\end{array}$ \\
\hline \multirow{2}{*}{30} & Control & $0.34 \pm 0.04$ & $0.16 \pm 0.02$ \\
& DDAVP & $0.22 \pm 0.02^{*}$ & $0.09 \pm 0.005^{*}$ \\
\cline { 2 - 4 } 60 & Control & $0.29 \pm 0.03$ & $0.12 \pm 0.003$ \\
& DDAVP & $0.24 \pm 0.02$ & $0.11 \pm 0.01$ \\
\cline { 2 - 4 } 90 & Control & $0.29 \pm 0.02$ & $0.11 \pm 0.005$ \\
& DDAVP & $0.25 \pm 0.04$ & $0.11 \pm 0.01$ \\
\cline { 2 - 4 } 120 & Control & $0.25 \pm 0.01$ & $0.10 \pm 0.003$ \\
& DDAVP & $0.23 \pm 0.03$ & $0.11 \pm 0.01$ \\
\cline { 2 - 4 } 150 & Control & $0.22 \pm 0.01$ & $0.09 \pm 0.003$ \\
& DDAVP & $0.20 \pm 0.03$ & $0.11 \pm 0.017$ \\
\cline { 2 - 4 } 180 & Control & $0.22 \pm 0.01$ & $0.09 \pm 0.00$ \\
& DDAVP & $0.23 \pm 0.04$ & $0.10 \pm 0.01$ \\
\hline
\end{tabular}

means \pm SEM; $n=18$; as compared with changes in control rats. ${ }^{*} p<0.05$; DDAVP, desmopressin; CA, cholic acid; CDCA+DCA, mixture of chenodeoxycholic acid+deoxycholic acid. 


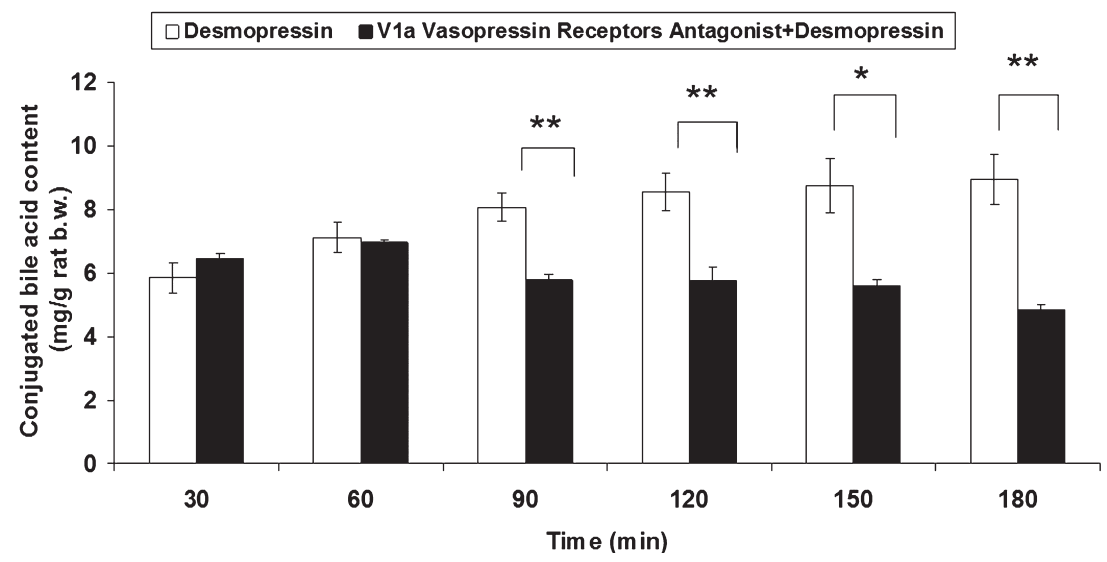

Figure 5. Effect of desmopressin on total conjugated bile acids content in $\mathrm{V}_{1 \mathrm{a}}$ vasopressin receptors antagonist+desmopressin-treated rats. Secreted bile was collected each half-hour during 3 hours of the experiment. Means \pm SEM; $n=18 ;{ }^{*} p<0.05 ;{ }^{* *} p<0.01$.

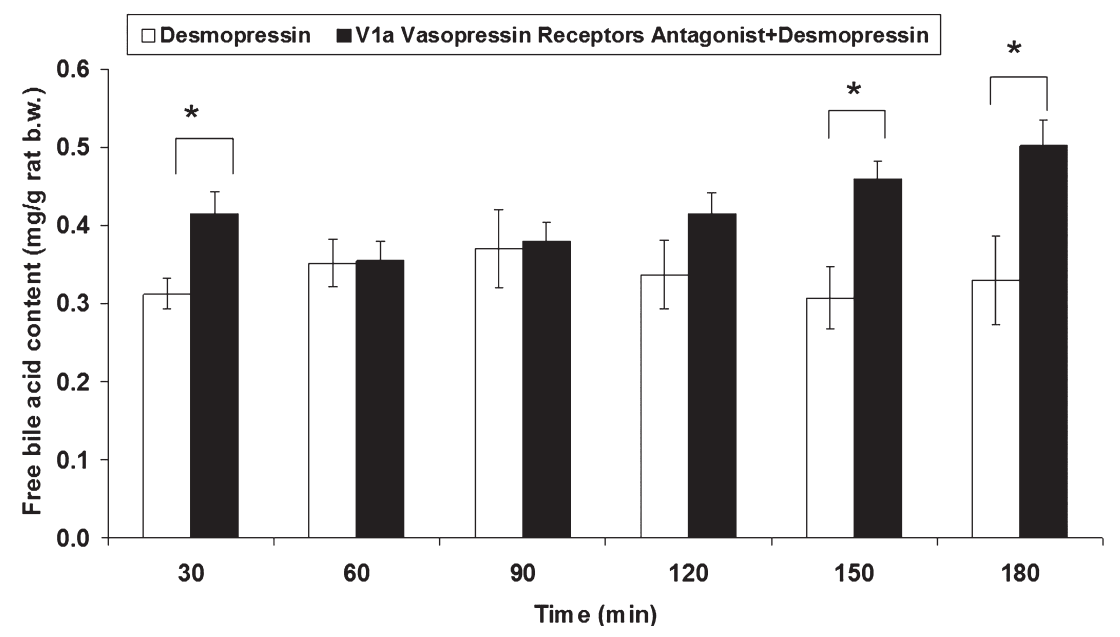

Figure 6. Effect of desmopressin on total free bile acids content in $\mathrm{V}_{1 \text { a }}$ vasopressin receptors antagonist+desmopressin-treated rats. Secreted bile was collected each half-hour during 3 hours of the experiment. Means \pm SEM; $n=18 ;{ }^{*} p<0.05$.

time of the experiment was diminished by $20.5 \%$ (from $18.4 \pm 0.8 \mathrm{mg} / \mathrm{g}$ to $14.7 \pm 0.7 \mathrm{mg} / \mathrm{g} ; p<0.05)$. In these series of experiments, absolute content of TCDCA+TDCA was diminished by $37.8 \%$ (from $11.9 \pm 0.8 \mathrm{mg} / \mathrm{g}$ to $7.14 \pm 0.3 \mathrm{mg} / \mathrm{g}$; $p<0.01)$. The content of glycine conjugated bile acids was insignificantly enhanced in the first and the second half-hour samples and it was diminished during the following two hours. The GCA content was changed in the third half-hour sample from $2.4 \pm 0.23 \mathrm{mg} / \mathrm{g}$ to $1.9 \pm 0.05 \mathrm{mg} / \mathrm{g}(p<0.05)$, in the fourth from $2.5 \pm 0.24 \mathrm{mg} / \mathrm{g}$ to $1.78 \pm 0.07 \mathrm{mg} / \mathrm{g}(p<$ 0.05 ), in the fifth from $2.4 \pm 0.21 \mathrm{mg} / \mathrm{g}$ to $1.8 \pm 0.06 \mathrm{mg} / \mathrm{g}$ ( $p<$ $0.05)$ and in the last from $2.6 \pm 0.23 \mathrm{mg} / \mathrm{g}$ to $1.5 \pm 0.02 \mathrm{mg} / \mathrm{g}$ $(p<0.01)$ in comparison with the results under DDAVP treatment, while the content of GCDCA+GDCA was significantly decreased by $51 \%$ (from $0.5 \pm 0.10 \mathrm{mg} / \mathrm{g}$ to $0.3 \pm$ $0.02 \mathrm{mg} / \mathrm{g} ; p<0.05$ ) only in the sixth half-hour sample. Under the effect of DDAVP in presence of $\mathrm{V}_{1 \mathrm{a}}$ vasopressin receptors antagonist the conjugated bile acids content at the second and the third hours of the experiment was significantly lower than under the effect of DDAVP alone (Fig. 5). Total absolute content of conjugated bile acids was diminished by $24.7 \%$ (from $49.1 \pm 2.88 \mathrm{mg} / \mathrm{g}$ to $37.9 \pm 1.14 \mathrm{mg} / \mathrm{g} ; p<0.05$ ). By contrast total free bile acids content was higher than in DDAVP-treated rats. As shown in Fig. 6, these differences were significant by $36.4 \%(p<0.05)$ in the first half-hour and by $70 \%(p<0.05)$ and by $56.5 \%(p<0.05)$ at the last hour of the experiment.

Although $\mathrm{V}_{1 \mathrm{a}}$ antagonism reduced DDAVP-stimulated choleresis, bile flow was higher in $\mathrm{V}_{1 \mathrm{a}}$ vasopressin antagonist+DDAVP-treated rats than in the control group (Fig. 7). It can thus be considered that not only hepatocytes $\mathrm{V}_{1 \mathrm{a}}$ vasopressin receptors activation, but also another differ- 


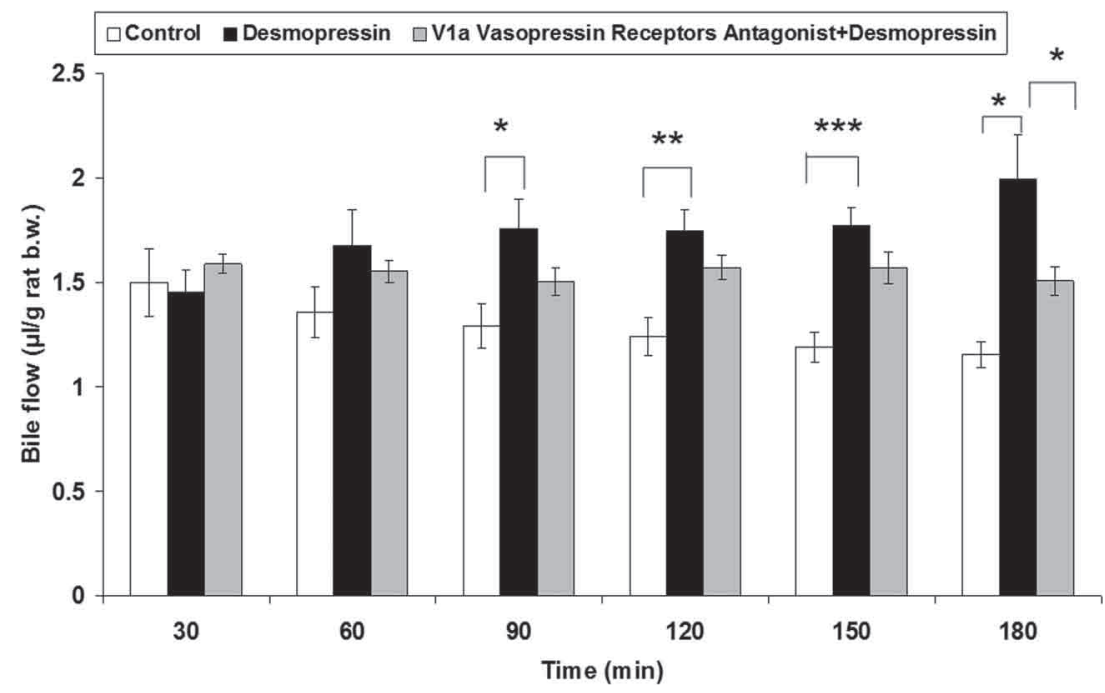

Figure 7. Effect of desmopressin on bile flow in $\mathrm{V}_{1 \mathrm{a}}$ vasopressin receptors antagonist+desmopressin-treated rats. Secreted bile was collected each half-hour during 3 hours of the experiment. Means \pm SEM; $n=18 ;{ }^{*} p<0.05 ;{ }^{* *} p<0.01 ;{ }^{* * *} p<0.001$.

ent mechanism is involved in the increasing of bile secretion in DDAVP-treated rats.

\section{Discussion}

In the present study, we found that DDAVP steadily increased the intensity of bile secretion during the all 3 hours of the experiment. It has been demonstrated that $\mathrm{ADH}$ is a regulator of bile flow in rats (Nathanson et al. 1992b). Nicous et al. 2003 showed that a very early hypothalamic release of ADH after partial hepatectomy involves in compensatory liver growth on the one hand. On the other hand $\mathrm{ADH}$ appears to stimulate bile flow during liver regeneration. It has been reported that $\mathrm{V}_{1 \mathrm{a}}$ vasopressin receptors gradient is correlated with choleretic effect of ADH (Serriere et al. 2001). It has been documented that $\mathrm{ADH}$ after binding to $\mathrm{V}_{1 \mathrm{a}}$ vasopressin receptors activates enzyme phospholipase $\mathrm{C}$, attached to the inside projection of the receptors. This enzyme catalyzes the breakdown of some phospholipids in the cell membrane, especially $\mathrm{PIP}_{3}$, while producing two different second messenger products, $\mathrm{IP}_{3}$ and $\mathrm{DAG}$. The last activates enzyme $\mathrm{PKC}$ and $\mathrm{IP}_{3}$ mobilizes calcium ions either from intracellular storage (Nathanson et al. 1992a) or directly from extracellular space (Brown 1999; Canaff et al. 2001; Sakwe et al. 2005). Calcium ions, as a second messenger stimulate actin microfilaments which are responsible for the movement of bile canaliculus, inducing their contractions for conducing bile from perivenous to periportal zone of the hepatic lobule and increasing bile flow (Nathanson et al. 1995; Gregory et al. 2004). On the other hand, Nathanson et al. 1999 reported that $\mathrm{ADH}(10 \mathrm{nmol} / \mathrm{l})$ in isolated perfused rat liver induced a transient $\sim 50 \%$ decrease in bile flow. They suggested that in liver, agonist-induced secretion is facilitated by intercellular communication via hepatocyte gap junctions. This result does not accord with our findings probably because of utilizing different experimental method. Moreover, the chemical structure of the peptide that we used differs from $\mathrm{ADH}$, as its hypertensive action is weaker than the natural hormone.

It is important that in the body, liver and kidneys have strong cooperation to support homeostasis. DDAVP is an analogue of $\mathrm{ADH}$, which in kidneys bonds to $\mathrm{V}_{2}$ vasopressin receptors and improves water reabsorption process. Therefore, the increased bile secretion under the effect of DDAVP is probably a compensatory mechanism for providing homeostasis. In addition, this peptide at the same time affects $\mathrm{V} 1_{\mathrm{b}}$ receptors in pituitary gland and in $\beta$ cells of pancreas, then stimulates secretion of ACTH, insulin and glucagon, so causes activation of DAG and PKC (Lee et al. 1995; Thibonnier et al. 1997; Yibchok-Anun et al. 1999). It is worthy to note that prolonged stimulatory effect of DDAVP in our experiments, which is different from natural hormone, is related to more prolonged half-life of DDAVP, which is 1.5-2.5 hours (Agerso et al. 2004; Robert and Clauser 2005).

The results indicated that DDAVP markedly affected the content of amino acid conjugated bile acids as compared with control rats. Results of our experiments agree with the findings of Kuhn et al. $(1988,1990)$. They found that in the isolated hepatocytes, $\mathrm{ADH}\left(10^{-11} \mathrm{~mol} / \mathrm{l}\right.$, added to the incubation environment) did not alter influx of tauro- and glycocholates into the hepatocytes, although directly stimulated the efflux of these bile acids from hepatocytes. The stimulation of efflux by $\mathrm{ADH}$ occurs at concentrations that 
approach the physiological circulating concentrations of the hormone. In addition, according to Schiff et al. (1999) under the effect of $\mathrm{ADH}$, those micelle-forming bile acids, such as taurocholate are better able than non-micelle-forming bile acids to maintain bile secretion. Meanwhile, in our experiments we observed diminishing the free bile acids secretion. Our results agree with the findings of Kuhn et al. (1988). They reported that $\mathrm{ADH}$ did not influence the concentration of CA, CDCA, and DCA in incubation environment, while caused a decrease in the level of free bile acids in hepatocytes. Possibly, it is related to the influence of $\mathrm{ADH}$ not only on the bile acids influx from the sinusoidal membrane of hepatocytes, but also on enzymes which participate in the synthesis of bile acids. Based on these results the effects of $\mathrm{ADH}$ on bile acids transport appear to be selective.

It is notable, that $\mathrm{ADH}$ forms $\mathrm{DAG}$, and the last activates PKC (Brown 1999; Sakwe et al. 2005). Activators of PKC, including $\mathrm{ADH}$ and synthetic phorbol ester, on the one hand stimulate transport of vesicles, containing cMOAT, to the apical membrane of hepatocytes in the short life cultures of hepatocyte couplets (Roma et al. 1999, 2000) and on the other hand, activate these proteins through phosphorylation (Nathanson et al. 1992). It should be noted that, $\mathrm{ADH}$ via activation of PKC in hepatocytes induces transfer of these transporter proteins to the basolateral membrane and enhances bile acids influx into the hepatocytes (Kubitz et al. 2001; Trauner and Boyer 2003). Moreover, condition in which the content of cMOAT on the canalicular domain of hepatocytes has been decreased, another transporter protein, $\mathrm{Mrp}_{3}$, localized on the basolateral domain of plasmatic membrane, increases the TCA efflux from hepatocytes. It is suggested that this process is a compensatory mechanism for deletion of bile acids from hepatocytes (Wolkoff and Cohen 2003).

We suggest that the $V_{1 a}$ vasopressin receptors antagonist modulates the action of DDAVP on bile secretion, as this peptide under $\mathrm{V}_{1 \mathrm{a}}$ vasopressin receptors blocking did not reveal its choleretic effect thoroughly. Our results agree with the findings of Kuhn et al. 1990. They reported that at a concentration ratio of $5: 1$ (antagonist to hormone) the $\mathrm{V}_{1}$ vasopressin antagonist, $\left(\mathrm{dCH}_{2}\right)_{5} \operatorname{Try}(\mathrm{Me}) \mathrm{AVP}$ inhibited the $\mathrm{ADH}$-induced efflux of TCA by approximately $82 \%$ and of GCA by $85 \%$. Since $V_{1 a}$ vasopressin receptors are present in plasmatic membrane of hepatocytes we suppose that different processes of bile formation by DDAVP are mediated through specific receptor binding.

In conclusion, DDAVP - the synthetic analogue of $\mathrm{ADH}$ markedly affected function of the liver parenchyma. This peptide $(1 \mathrm{ng} / 100 \mathrm{~g}$ rat b.w.) at concentrations nearly equal to physiological blood level concentrations of $\mathrm{ADH}$, changed intensity of bile flow and markedly modified bile chemical compositions secretion that was reflected in their increased biliary total contents. It certifies the role of DDAVP in regula- tion of physiological-biochemical processes in liver. It is suggested that DDAVP stimulates the secretion of conjugated bile acids within bile. Meanwhile the peptide has an opposite effect on free bile acids secretion. The last, obviously, is related to the intensified conjugation process, especially taurine conjugation under the effect of peptide. These qualitative changes of bile compositions improve antilithogenic bile properties and decrease the potential forming of biliary stones. The results suggest that $\mathrm{V}_{1 \mathrm{a}}$ vasopressin receptors activation mediates the choleretic effect of DDAVP on liver.

Although the presented data in acute experiments revealed the choleretic effect of DDAVP, there are several factors such as narcotizing, trauma, rat special peculiarity (lack of gall bladder, high metabolism intensity and peculiarity of bile acids spectrum) that do not allow evaluating the effects of DDAVP on choleresis, objectively and comprehensively. Since DDAVP is a medicine that is commonly used in clinic, it seems important to investigate its effects on bile secretion in chronic experiments in another species of animals.

Acknowledgments. We wish to thank Dr. Arman Mehdi Javanshiri (American Medical Centers, Kyiv) for editing and revision of this manuscript.

\section{References}

Agerso H., Larsen L. S., Riis A., Lovgren U., Karlsson M. O., Senderovitz T. (2004): Pharmacokinetics and renal excretion of desmopressin after intravenous administration to healthy subjects and renally impaired patients. Br. J. Clin. Pharmacol. 58, 352-358; doi:10.1111/j.1365-2125.2004.02175.x

Barberis C., Mouillac B., Durroux T. (1998): Structural bases of vasopressin/oxytocin receptor function. J. Endocrinol. 156, 223-229; doi:10.1677/joe.0.1560223

Brown E. M. (1999): Physiology and pathophysiology of the extracellular calcium-sensing receptor. Am. J. Med. 106, 238-253; doi:10.1016/S0002-9343(98)00418-5

Canaff L., Petit J. L., Kisiel M., Watson P. H., Gascon-Barre M., Hendy G. N. (2001): Extracellular calcium-sensing receptor is expressed in rat hepatocytes: coupling to intracellular calcium mobilization and stimulation of bile. J. Biol. Chem. 276, 4070-4079; doi:10.1074/jbc.M009317200

Divald A., Simpser E., Fisher S. E., Karl P. I. (1994): Vasopressin and phorbol-12, 13-dibutyrate inhibit glucagon- or cyclic AMP-stimulated taurocholate uptake in isolated rat hepatocytes. Hepatology 20, 159-165

Gregory R. B., Hughes R., Barritt G. J. (2004): Induction of cholestasis in the perfused rat liver by 2 -aminoethyl diphenylborate, an inhibitor of the hepatocyte plasma membrane $\mathrm{Ca}^{2+}$ channels. J. Gastroenterol. Hepatol. 19, 1128-1134; doi:10.1111/j.1440-1746.2004.03417.x

Hirata K., Nathanson M. H. (2001): Bile duct epithelia regulate biliary bicarbonate excretion in normal rat liver. Gastroenterology 121, 396-406; doi:10.1053/gast.2001.26280 
Kubitz R., Huth C., Schmitt M., Horbach A., Kullak-Ublick G., Haussinger D. (2001): Protein kinase C-dependent distribution of the multidrug resistance protein 2 from the canalicular to the basolateral membrane in human HepG2 cells. Hepatology 34, 340-350; doi:10.1053/ jhep.2001.25959

Kuhn W. F, Gewirtz D. A. (1988): Stimulation of taurocholate and glycocholate efflux from the rat hepatocyte by arginine vasopressin. Am. J. Pysiol. 254, G732-740

Kuhn W. F., Heuman D. M., Vlahcevic Z. R., Gewirtz D. A. (1990): Receptor-mediated stimulation of taurocholate efflux from the rat hepatocyte and the ex vivo perfused rat liver. Eur. J. Pharmacol. 175, 117-128; doi:10.1016/00142999(90)90222-R

Lee B., Yang C., Chen T. H., Al-Azawi N., Hsu W. H. (1995): Effect of AVP and oxytocin on insulin release: involvement of $\mathrm{V}_{1 \mathrm{~b}}$ receptors. Am. J. Physiol. Endocrinol. Metab. 269, E1095-1100

Lidofsky S. D., Xie M. H., Sostman A., Scharschmidt B. F., Fitz J. G. (1993): Vasopressin increases cytosolic sodium concentration in hepatocytes and activates calcium influx through cation-selective channels. J. Biol. Chem. 268, 14632-14636

Montero S., Mendoza H., Valles V., Lemus M., Alvarez-Buylla R., de Alvarez-Buylla E. R. (2006): Arginine-vasopressin mediates central and peripheral glucose regulation in response to carotid body receptor stimulation with $\mathrm{Na}$-cyanide. J. Appl. Physiol. 100, 1902-1909; doi:10.1152/japplphysiol.01414.2005

Nathanson M. H., Gautam A., Ng O. C., Bruck R., Boyer J. L. (1992a): Hormonal regulation of paracellular permeability in isolated hepatocytes couplets. Am. J. Physiol. 262, G1079-1086

Nathanson M. H., Gautam A., Bruck R., Isales C. M., Boyer J. L. (1992b): Effects of $\mathrm{Ca}^{2+}$ agonists on cytosolic $\mathrm{Ca}^{2+}$ in isolated hepatocytes and on bile secretion in the isolated perfused rat liver. Hepatology 15, 107-116; doi:10.1002/ hep.1840150119

Nathanson M. H., Burgstahler A. D., Mennone A., Fallon M. B., Gonzalez C. B., Saez J. C. (1995): $\mathrm{Ca}^{2+}$ waves are organized among hepatocytes in the intact organ. Am. J. Physiol. Gastrointest. Liver Physiol. 269, G167-171

Nathanson M. H., Rios-Velez L., Burgstahler A. D., Mennone A. B. (1999): Communication via gap junctions modulates bile secretion in the isolated perfused rat liver. Gastroentrology 116, 1176-1183; doi:10.1016/S00165085(99)70021-1

Nicous A., Serriere V., Prigent S., Bucherie S., Combettes L., Guillon G., Alonso G., Tordjmann T. (2003): Hypothalamic vasopressin release and hepatocyte $\mathrm{Ca}^{2+}$ signaling during liver regeneration: an interplay stimulating liver growth and bile flow. FASEB J. 17, 1901-1903

Robert J., Clauser E. R. (2005): Vasopressin receptors: structure/function relationships and signal transduction in target cells. J. Soc. Biol. 199, 351-359; doi:10.1051/jbio:2005037
Roma M. G., Ahmed-Choudhury J., Coleman R. (1999): The protein kinase inhibitor 1-(5-isoquinolinylsulfonyl)-2-methylpiperzine (H-7) prevents and reverses $\mathrm{Ca}^{2+}$-mediated injury in isolated rat hepatocyte couplets. Toxicol. Appl. Pharmacol. 161, 192-201; doi:10.1006/taap.1999.8801

Roma M. G., Milkiewicz P., Elias E., Coleman R. (2000): Control by signaling modulators of the sorting of canalicular transporters in rat hepatocyte couplets: role of the cytoskeleton. Hepatology 32, 1342-1356; doi:10.1053/jhep.2000.20519

Saito M., Tahara A., Sugimoto T. (1997): 1-desamino-8-d-arginine vasopressin (dDAVP) as an agonist on $\mathrm{V}_{1 \mathrm{~b}}$ vasopressin receptor. Biochem. Pharmacol. 53, 1711-1717; doi:10.1016/ S0006-2952(97)00070-1

Sakwe A. M., Rask L., Gylfe E. (2005): Protein kinase C modulates agonist-sensitive release of $\mathrm{Ca}^{2+}$ from internal stores in HEK293 cells overexpressing the calcium sensing receptor. J. Biol. Chem. 280, 4436-4441; doi:10.1074/jbc. M411686200

Schiff E. R., Sorrel F., Maddrey W. C. (1999): Bile formation. In: Schiff's Disease of the Liver. (Eds. J. L. Boyer and M. Nathanson), pp.119-139, Lippincott-Raven publisher, Philadelphia

Serriere V., Berthon B., Boucherie S., Acquemin E. J., Guillon G., Claret M. T. (2001): Vasopressin receptor distribution in the liver controls calcium wave propagation and bile flow. FASEB J. 15, 1484-1486

Thibonnier M., Preston J. A., Dulin N., Wilkins P. L., Berti-Mattera L. N., Mattera R. (1997): The human V3 pituitary vasopressin receptor: ligand binding profile and density-dependent signaling pathways. Endocrinology 138, 4109-4122; doi:10.1210/en.138.10.4109

Tran D., Durroux T., Stelly N., Seyer R., Tordjmann T., Combettes L., Claret M. (1999a): Visualization of cell surface vasopressin $\mathrm{V}_{1 \mathrm{a}}$ receptors in rat hepatocytes with a fluorescent linear antagonist. J. Histochem. Cytochem. 47, 401-410

Tran D., Stelly N., Tordjmann T., Durroux T., Noelle Dufour M., Forchioni A., Seye R., Claret M., Guillon G. (1999b): Distribution of signaling molecules involved in vasopressininduced $\mathrm{Ca}^{2+}$ mobilization in rat hepatocytes multyplets. J. Histochem. Cytochem. 47, 601-616

Trauner M., Boyer J. L. (2003): Bile salt transporters: molecular characterization, function, and regulation. Physiol. Rev. 83, 633-671

Wang Y., Crofton J. T., Bealer S. L., Share L. (1997): Sexual dimorphism in regional blood flow responses to vasopressin in conscious rats. Am. J. Physiol. 273, R1126-1131

Wolkoff A. W., Cohen D. E. (2003): Bile acid regulation of hepatic physiology, hepatocyte transport of bile acid. Am. J. Physiol. Gastrointest. Liver. Physiol. 284, G175-179

Yibchok-Anun S., Cheng H., Heine P. A., Hsu W. H. (1999): Characterization of receptors mediating AVP- and OT-induced glucagon release from the rat pancreas. Am. J. Physiol. Endocrinol. Metab. 277, E56-62

Received: August 26, 2009

Final version accepted: February 24, 2010 